\title{
Fundamentals of Presbyopia: visual processing and binocularity in its transformation
}

\author{
Olga I. Rozanova ${ }^{1 *}$, Andrey G. Shchuko ${ }^{1,2}$ and Tatyana S. Mischenko ${ }^{1}$
}

\begin{abstract}
Background: The accommodation has considerable interactions with the pupil response, vergence response and binocularity. The transformation of visual reception processing and the changes of the binocular cooperation during the presbyopia development are still poorly studied. So, the regularities of visual system violation in the presbyopia formation need to be characterized. This study aims to reveal the transformation of visual reception processing and to determine the role of disturbances in binocular interactions in presbyopia formation.

Methods: This study included 60 people with emmetropic refraction, uncorrected distance visual acuity 1.0 or higher (decimal scale), normal color perception, without concomitant ophthalmopathology. The first group consisted of 30 people (from 18 to 27 years old) without presbyopia, the second cohort comprised 30 patients (from 45 to 55 years old) with presbyopia. The eyeball anatomy and optics were evaluated using ultrasound biomicroscopy, aberrometry, and pupillometry. The functional state of the visual system was investigated under monocular and binocular conditions. The registration of the disparate fusional reflex limits was performed by the original technic using a diploptic device which facilitated investigation of the binocular interaction under natural conditions without the accommodation response, but with the different vergence load. The disparate fusional reflex was analyzed using the proximal and distal fusion borders, and the convergence and divergence fusion borders. The calculation of the area of binocularity field was performed in $\mathrm{cm}^{2}$.

Results: The presbyopia formation is characterized by a change in an intraocular anatomy, optics, visual processing, and binocularity. The processes of binocular interaction inhibition make a significant contribution to the misalignment of the visual perception. The modification of the proximal, distal and convergence fusion borders was determined. It was revealed that $87 \%$ of the presbyopic patients had binocularity shortage, whereas the reduction of binocularity field area in extreme grade was seen in $6 \%$ of cases.
\end{abstract}

Conclusions: The presbyopia formation is accompanied by a significant reorganization of the visual system activity and by the creation of the new visual processing interactions. These data may be useful in presbyopia surgery.

Keywords: Presbyopia, Binocularity, Visual processing, Visual reception

\footnotetext{
* Correspondence: olgrozanova@gmail.com

'Irkutsk branch of S. Fyodorov Eye Microsurgery Federal State Institution,

Irkutsk, Russian Federation

Full list of author information is available at the end of the article
} 


\section{Background}

According to the International Classification of Diseases (ICD-10, version: 2010) presbyopia belongs to the class of refraction and accommodation disturbance and is slow, age-related and irreversible accommodation decline. Currently, over 1.7 billion people in the world are afflicted with presbyopia [1]. The problem appears in people at the age of $40-45$ years, which is the period of maximal professional and creative activity involving analyses of a significant volume of visual information [2-4].

The problem of presbyopia correction is an actual task, but in spite of the active introduction of advanced methods, the question about adequate presbyopia correction remains open and unsettled [5]. For the compensation of accommodation deficit, different variants of a multifocal optical system creation have been described [1, 5-12].

But the creation of a multifocal monocular optical system or anisometropic binocular optical system is closely associated with the adaptation processes, which are very complicated in some patients. The multifocal monocular optical system does not have any physiological analogs [13-15]. Regardless of the multifocal IOL model, there is always a proportion of patients who complain of the visual dysphotopsia as blurring, misting, "holographic" view, 3D - view. In $5 \%$ of cases, this dysphotopsia syndrome becomes rigid and is an indication for IOL explantation [16]. The reasons for the visual dysphotopsia are not clear enough. The explantation of multifocal intraocular lens is debated as an "army method of refractive surgery" [16] and is about 3 to $10 \%$ according to the data by different authors [16-20].

Most of the presbyopia theories consider the intraocular changes purely. The presbyopia is mainly viewed as an accommodation decrease determined by the reduction of lenticular elasticity and changing lens suspension apparatus [21-24]. At the same time, the accommodative response is a part of the near synkinetic reflex. The accommodation has significant interactions with the pupil response, vergence response, and binocularity.

However, based on the theory of functional systems, the loss of useful component in the body's activity is accompanied by the measures to compensate or to adapt for it [25-27]. Therefore, the reduction of the accommodative response that underlies the presbyopia development must be inevitably accompanied by the imbalance among the components of the near synkinetic reflex. How does the accommodation decrease influence the ocular motor forces which are responsible for the stable constant visual image? This problem has not been solved yet.

The changes of the binocular cooperation during the presbyopia development are still poorly studied. According to our previous studies, there is some deficit of binocular cooperation in age-related accommodation loss [28]. Besides, the aging-induced accommodation decrease is strongly linked with other physiological aging processes and the degradational changes of sensory neurons. The normal aging is accompanied by the visual acuity decrease, contrast sensibility decrease, color perception changing, stereoacuity decrease [29-32]. The age-related reduction of stereovision is marginally correlated with fusional ability decrease [33]. But what remains unclear is the role of binocular disorders among mechanisms underlying presbyopia pathogenesis. Therefore, comprehending the binocular interaction changes in people with presbyopia is a critical issue, and the regularities of visual system violation in the presbyopia formation need to be characterized.

The purpose of this study is to examine the transformation of visual reception processing and to determine the role of binocular interactions disturbance in presbyopia formation.

\section{Methods \\ Subjects}

The study adhered to the tenets of Helsinki Declaration and was approved by the Institution Research and Ethics Committee (protocol number 8/13 from 25/11/2013). All patients were adequately informed and signed a consent form. Of the 60 people examined, the first group consisted of 30 people (from 18 to 27 years old) without presbyopia, and the second group comprised 30 patients (from 45 to 55 years old) with presbyopia.

The criteria for inclusion in this study comprise the presence of emmetropic refraction (i.e., the spherical equivalent of cycloplegic measurements from $+0.25 \mathrm{D}$ to $-0.25 \mathrm{D})$, uncorrected distance visual acuity of each eye 1.0 (decimal scale) or higher, normal color perception, ophthalmopathology absence. All patients of the second group complained of the insufficient near vision, and they made use of the glasses.

Considering that binocularity correlates the heterophoria value and interpupillary distance [34, 35], the exclusion criteria comprised a heterophoria degree greater than five prism diopter, the pupillary distance less than $62 \mathrm{~mm}$ and greater than $64 \mathrm{~mm}$.

\section{Measurements}

All patients had a full ophthalmological examination including the evaluation of 80 parameters of eye anatomy, visual processing, and binocularity.

\section{Assessment of the eye anatomy and the physiological optics}

The refractive error was the average spherical equivalent of five cycloplegic measurements taken with an autorefractor/ keratometer (KR8800, Topcon, Japan). All cycloplegic measurements were made $25 \mathrm{~min}$ after the administration of $1 \%$ tropicamide ( 2 drops during 5 min interval twice).

The other investigations were performed 7-10 days later. 
The amplitude of accommodation (AA) was measured using a minus lens method. The subjects were asked to fixate N8 target at a distance of $40 \mathrm{~cm}$. Then minus lenses were introduced in $0.25 \mathrm{D}$ steps until the patient reported the first sustained blur that could not be cleared by the further conscious effort. This procedure was done for each eye first monocularly and then binocularly. The total AA was estimated as the endpoint minus lens which was possible to see the target at $40 \mathrm{~cm}$ under binocular conditions. The AA measurement in people with presbyopia was done using the near addition lens.

The axial length, lens thickness, anterior chamber (AC) measurements were made with the help of an ultrasound biometer (AL-3000, Tomey, Japan). An average of three measurements for each parameter was used. Ultrasound biomicroscopy (UBM) measurements were made using HiScan 2000 (Optikon, Italy), and UBM was done in the supine position as described by C. Pavlin and F. Foster [36]. Images from the iris root to the pars plicata zone were obtained in 12 o'clock direction. The ciliary body thickness in cross section and the length of anterior portion Zinn's ligament were examined. The ocular wavefront aberration across a $3 \mathrm{~mm}$ zone in the pupil and the pupil diameter (under photopic and mesopic conditions) were obtained using the principle of automated retinoscopy (OPD-Scan, NIDEK, Japan). The anterior chamber volume, iris and lens configuration, corneal aberrations, lens light transmission, were fixed using Pentacam (Oculus Optikgeräte GmbH, Germany).

\section{Assessment of visual processing under monocular conditions}

The distance visual acuity and the near visual acuity were measured with logical geometric scale Bailey-Lovie ( $\log$ MAR). Other examinations included evaluation of the contrast sensitivity at spatial frequencies 3, 6, 12, 18 cycles per degree (CSV-10000E, VectorVision, USA), the threshold of light sensitivity (EP3000, Tomey, Japan), the flicker fusion threshold, the amplitude and implicit time of maximal electric retinal response, and the amplitude and implicit time of visual evoked potentials (EP1000, Tomey, Japan).

\section{Binocularity assessment}

For this purpose, the data reflecting the different levels of binocular interaction were systematized. These include the near physiological diplopia, the stereovision test Lang I\&II, and the binocularity field (spatial limits of disparate fusional reflex).

To induce the physiological diplopia, each patient was asked to look into the far distance $(5 \mathrm{~m})$. Then a nearlying target (in the distance $10 \mathrm{~cm}$, i.e., not in the horopter curve) was presented. The presence (yes/no) of double virtual objects was fixed.
In the case of physiological diplopia, the registration of the disparate fusional reflex limits was performed. For this, a diploptic device (AVIS 01, Krasnogvardeec, Russia) was used, which facilitated investigation of the binocular interaction under natural conditions without the accommodation response, but with the different vergence load [37-41]. The first point of the measurement is $40 \mathrm{~cm}$. Then the double targets were moved inwards until the virtual stereo image was observed (Fig. 1). It was a point of binocularity without vergence load.

The change in the distance between the centers of the double near lying tests (p) and the distance from the eyes to the targets (n) while maintaining of the virtual binocular image perception makes it possible to define the fusional reflex limits in space. Then the targets were moved increasingly inward and outward to force the vergence response (Fig. 2). There were some points of maximum convergence and divergence. The patient reported all the visual images which were recorded.

The disparate fusional reflex was analyzed using the following parameters:

1. The proximal fusion border (PF) and distal fusion border (DF) were determined while the double targets were approaching and moving away (Fig. 2). The difference between these parameters corresponds to the length of the binocularity field.

2. The convergence fusion border $(\mathrm{CF})$ and the divergence fusion border (DivF) were determined with the help of the decrease and the increase of the distance between the double targets (the point of the measurement is $40 \mathrm{~cm}$ from the eyes). The

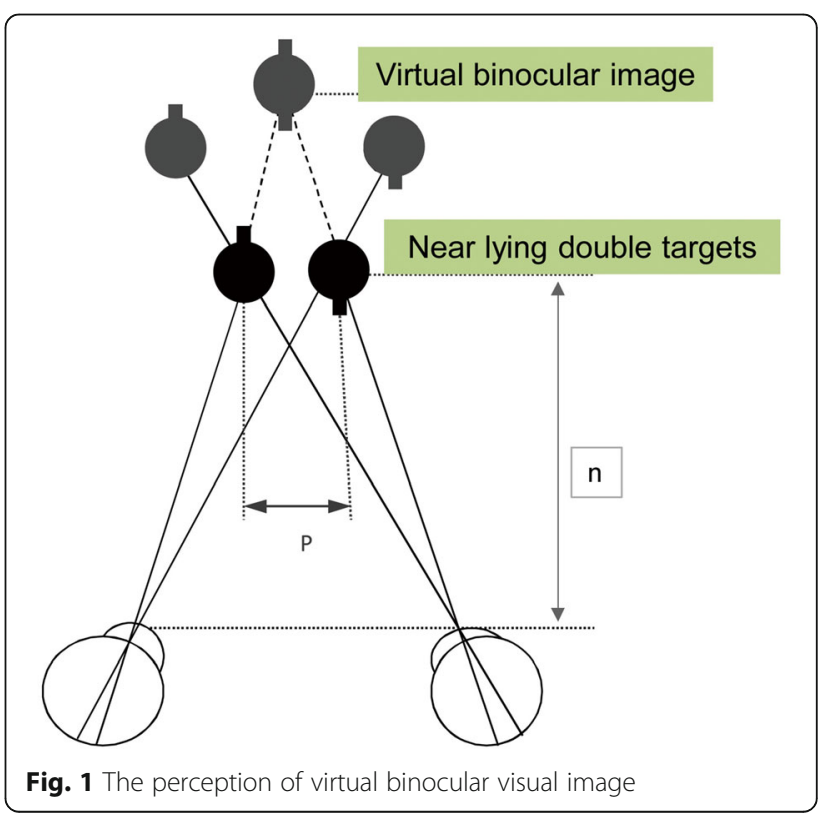




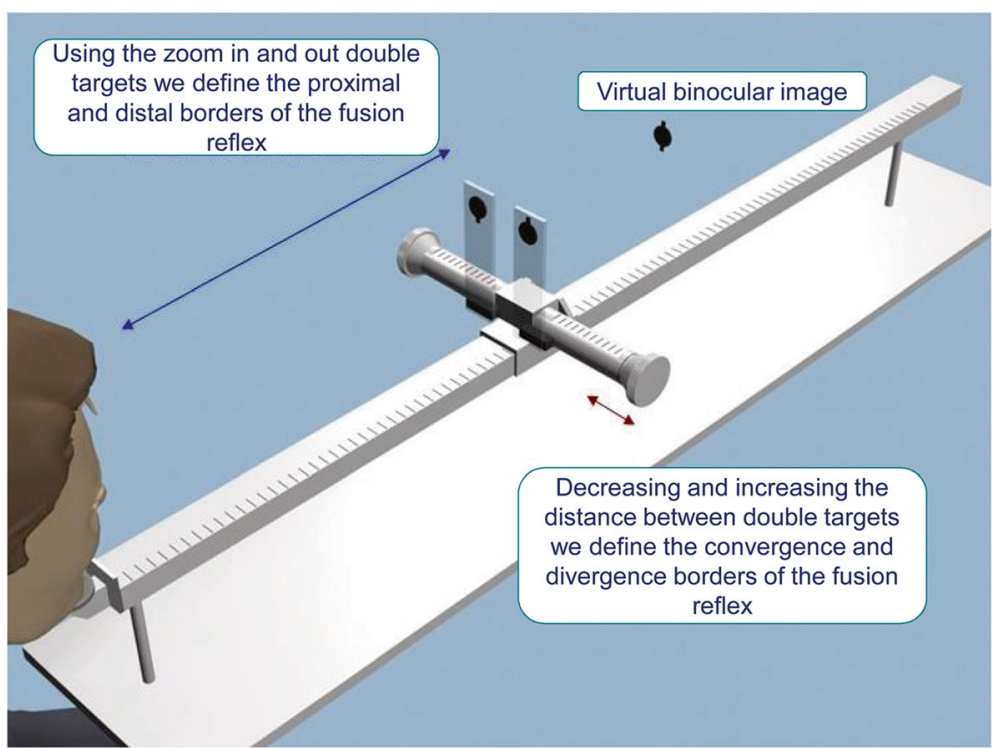

Fig. 2 Method of Assessing the Disparate Fusion Reflex Borders

difference between these parameters corresponds to the width of the binocularity field.

3. Finally, we performed the calculation of the binocularity field area (A) in $\mathrm{cm}^{2}$ (Fig. 3).

\section{Statistical analysis}

All data were analyzed with a spreadsheet application (Statistica ver. 8.0; StatSoft Inc., USA). The data were represented as the mean value \pm standard deviation (Mean \pm SD). The Shapiro-Wilk test was used for assessing of normality distribution. The statistical differences in measured values were analyzed using a t-test. The critical level of significance (p) upon the examination of statistical hypotheses was 0.05 . The comparison analysis, the Pearson correlation analysis, and the logistic regression models were done. The Pearson correlation coefficient with absolute values equal to or greater than 0.7 with $p<0.001$ was accepted as the close relation. The

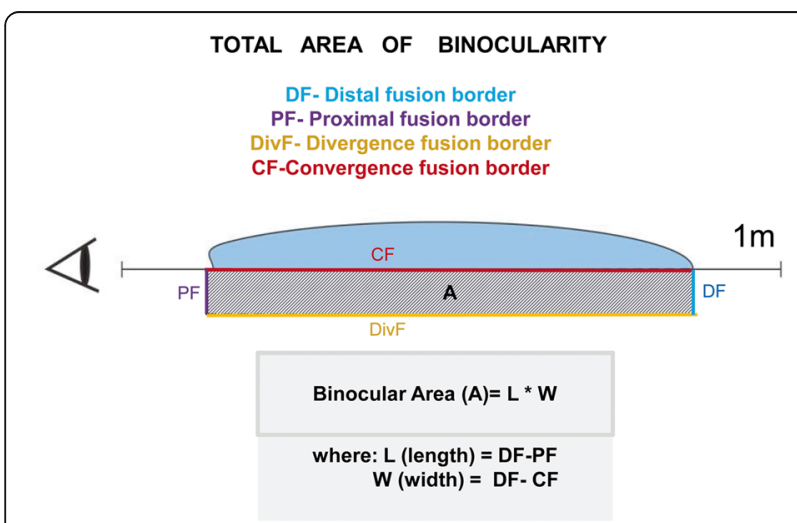

Fig. 3 Calculation of the Binocularity Field Area discriminant function analysis (DFA) was used for the selection of the analytes that maximally discriminated the studied groups. The DFA was built in a step-wise manner after direct standardization. The final discriminatory power of each analyte was characterized by a partial Wilk's Lambda coefficient; 1.0 (no discriminatory power) to 0.0 (perfect discriminatory power). The Mahalanobis distance $\mathrm{D}^{2}$ between centroid values for each group was measured.

\section{Results}

The baseline features of the study population were summarized in Table 1. The mean patient age was $22.3 \pm$ 3.2 years in the first group, and $52.4 \pm 2.2$ years in the second group. The groups did not differ in gender, spherical refraction equivalent, eye globe axial length, oculomotor status. In the first (control) group, the mean accommodation amplitude was $6.93 \pm 1.12 \mathrm{D}$ (minimum

Table 1 Studied Groups Descriptive Statistics (M \pm SD)

\begin{tabular}{llll}
\hline Characteristics & Control & Presbyopia & $P$-value \\
\hline Age, years & $22.3 \pm 3.2$ & $52.4 \pm 2.2$ & 0.0001 \\
Female: Male & $15: 15$ & $15: 15$ & - \\
$\begin{array}{l}\text { Mean spherical equivalent } \\
\text { of refraction, D }\end{array}$ & $0.2 \pm 0.1$ & $0.2 \pm 0.2$ & 1.00 \\
Axial length, mm & $23.5 \pm 0.5$ & $23.5 \pm 0.4$ & 1.00 \\
Keratometry, ax 90, $\mathrm{D}$ & $43.2 \pm 1.3$ & $43.3 \pm 1.1$ & 0.61 \\
Keratometry, ax 180, $\mathrm{D}$ & $43.0 \pm 1.1$ & $43.1 \pm 1.1$ & 0.62 \\
Amplitude of accommodation, D & $6.93 \pm 1.12$ & $1.99 \pm 0.89$ & 0.0001 \\
$\begin{array}{l}\text { Mean prism equivalent of } \\
\text { distance heterophoria, PD }\end{array}$ & $-1.2 \pm 0.2$ & $-1.1 \pm 0.3$ & 0.88 \\
\hline$D=$ diopter; $P D=$ prism diopter & & & \\
\hline
\end{tabular}


5.75 D, maximum 10.0 D). All patients with presbyopia had a decreased accommodation: the mean accommodation amplitude was $1.99 \pm 0.89 \mathrm{D}$ (minimum $0.5 \mathrm{D}$, maximum $4.0 \mathrm{D})$.

\section{Intraocular anatomy and optics}

The presbyopia formation is characterized by a change in an intraocular anatomy. Significant differences were detected in the anterior-posterior size of the lens - from $3.73 \pm 0.23$ to $4.41 \pm 0.21$ ( $p=0.0001)$. The optical density (light transmission coefficient) of the lens increased in the nuclear area from $15.5 \pm 1.2$ to $26.6 \pm 3.4 \%(\mathrm{p}=0.0001)$, and in the cortical layers - from $9.1 \pm 0.9$ to $10.8 \pm 1.3 \%$ $(p=0.03)$. The change of the intraocular anatomy was expressed as: the decrease of the ciliary body thickness (in the inner top projection) from $0.82 \pm 0.10$ to $0.63 \pm$ $0.11 \mathrm{~mm}(p=0.001)$, the increase of the distance between the trabecula and the ciliary processes from $0.79 \pm 0.10$ to $1.02 \pm 0.11 \mathrm{~mm}(p=0.001)$, and the shortage of the front portion Zinn ligament length from $1.23 \pm 0.31$ to $1.04 \pm$ $0.26 \mathrm{~mm}(p=0.002)$.

The variation of both static and dynamic components of the optical physiological system was established in the eyes of presbyopic patients. This was evidenced by a significant increase of the total root mean square wavefront errors (from $0.13 \pm 0.04$ to $0.17 \pm 0.05 \mu \mathrm{m}$ in pupil diameter $3 \mathrm{~mm}, p=0.0001$ ) and the corneal root mean square wavefront aberrations. In patients with presbyopia, an increase in the Zernike coefficients of the corneal spherical aberration $Z_{4}^{0}$ from $0.17 \pm 0.05$ to $0.23 \pm 0.06 \mu \mathrm{m}$ $(p=0.0001)$ was observed. Also, a significant decrease of the pupil excursion was found. The photopic pupil diameter decreased from $3.81 \pm 0.76$ to $3.35 \pm 0.78 \mathrm{~mm}$ $(\mathrm{p}=0.0001)$ whereas the mesopic pupil diameter decreased from $6.47 \pm 0.56$ to $5.50 \pm 0.94 \mathrm{~mm}(\mathrm{p}=0.0001)$.

\section{Monocular visual characteristics}

In the next step, a comprehensive study of the sensory activity of the visual system was carried out. The patients with presbyopia had a decrease not only in accommodation amplitude and uncorrected near visual acuity but also in the most of the visual reception parameters (Table 2).

A significant decrease of the contrast sensitivity in low and high spatial frequency ranges, the average values of the b-wave ERG maximum amplitude, the flicker fusion threshold and an increase in the a-wave and b-wave ERG maximum latency were found in patients with presbyopia.

\section{Binocularity}

The change in the perception Lang stereo tests was not significant.

A study of binocular cooperation showed an inhibition of the near physiological diplopia in $20 \%$ of the patients with presbyopia.
Table 2 Comparisons of visual characteristics in studied groups $(\mathrm{M} \pm \mathrm{SD})$

\begin{tabular}{llll}
\hline Characteristics & Control & Presbyopia & $P$-value \\
\hline UDVA, logMAR & $-0.071 \pm 0.045$ & $-0.003 \pm 0.026$ & 0.0001 \\
UNVA, logMAR & $0.033 \pm 0.043$ & $0.575 \pm 0.215$ & 0.0001 \\
CSS, frequency $3 \mathrm{cpd}$, units & $7.41 \pm 0.49$ & $5.66 \pm 0.54$ & 0.0001 \\
CSS, frequency $6 \mathrm{cpd}$, units & $7.54 \pm 0.45$ & $6.95 \pm 0.50$ & 0.01 \\
CSS, frequency 12 cpd, units & $7.41 \pm 0.45$ & $6.83 \pm 0.37$ & 0.01 \\
CSS, frequency 18 cpd, units & $7.41 \pm 0.45$ & $6.02 \pm 0.55$ & 0.0001 \\
Threshold of retina sensitivity, & $27.9 \pm 1.1$ & $24.6 \pm 3.5$ & 0.01 \\
dB & & & \\
Implicit time VEP on flash, & $32.1 \pm 14.5$ & $29.1 \pm 10.5$ & 0.19 \\
msec & & & \\
Amplitude VEP on flash, $\mu V$ & $99.7 \pm 6.4$ & $100.6 \pm 8.2$ & 0.17 \\
Implicit time a-wave max & $15.7 \pm 7.5$ & $21.3 \pm 11.0$ & 0.001 \\
ERG, msec & & & \\
Amplitude a-wave max & $149.7 \pm 36.0$ & $139.8 \pm 42.7$ & 0.17 \\
ERG, $\mu$ V & & & \\
Implicit time b-wave max & $36.2 \pm 3.2$ & $45.9 \pm 6.6$ & 0.0001 \\
ERG, msec & & & \\
Amplitude b-wave max & $311.8 \pm 57.7$ & $287.0 \pm 63.4$ & 0.027 \\
ERG, $\mu$ V & & $32.3 \pm 2.9$ & 0.001 \\
\hline FFT, Hz & $34.7 \pm 2.1$ &
\end{tabular}

$U D V A=$ uncorrected distance visual acuity; UNVA = uncorrected near visual acuity; CSS = contrast spatial sensitivity; VEP = visual evoked potentials; $E R G=$ electroretinogram; $F F T=$ flicker fusion threshold

There were multiple changes. These include a significant distortion of the binocular interaction zone with the reduction of total binocularity area, shift in the space towards the near focal point, and the fusion neutralization in the convergence zone. The changes in the proximal, distal and convergence fusion borders were determined (Table 3).

The regressions between disparate fusion reflex limits and accommodation amplitude are shown in Fig. 4. In the first (control) group, the mean area of binocularity field was $365.6 \pm 45.1 \mathrm{~cm}^{2}$ (minimum $280 \mathrm{~cm}^{2}$, maximum

Table 3 Comparisons of Fusion Reflex Characteristics in Study Groups (M \pm SD)

\begin{tabular}{llll}
\hline Characteristics & Control & Presbyopia & $P$-value \\
\hline Proximal fusion border, cm & $5.23 \pm 1.58$ & $18.90 \pm 6.85$ & 0.0001 \\
Distal fusion border, cm & $90.05 \pm 7.35$ & $69.20 \pm 12.21$ & 0.0001 \\
$\begin{array}{l}\text { Convergence fusion border, } \\
10^{-1} \mathrm{~cm}\end{array}$ & $24.83 \pm 6.14$ & $30.31 \pm 6.91$ & 0.0001 \\
$\begin{array}{l}\text { Divergence fusion border, } \\
10^{-1} \mathrm{~cm}\end{array}$ & $63.38 \pm 3.55$ & $58.21 \pm 5.61$ & 0.056 \\
$\begin{array}{l}\text { Length of binocularity } \\
\text { field, cm }\end{array}$ & $84.78 \pm 7.75$ & $50.82 \pm 16.05$ & 0.0001 \\
$\begin{array}{l}\text { Width of binocularity field, } \\
10^{-1} \mathrm{~cm}\end{array}$ & $41.88 \pm 3.35$ & $30.39 \pm 6.34$ & 0.0001 \\
Area of binocularity field, $\mathrm{cm}^{2}$ & $365.60 \pm 45.10$ & $174.40 \pm 87.70$ & 0.0001 \\
\hline
\end{tabular}



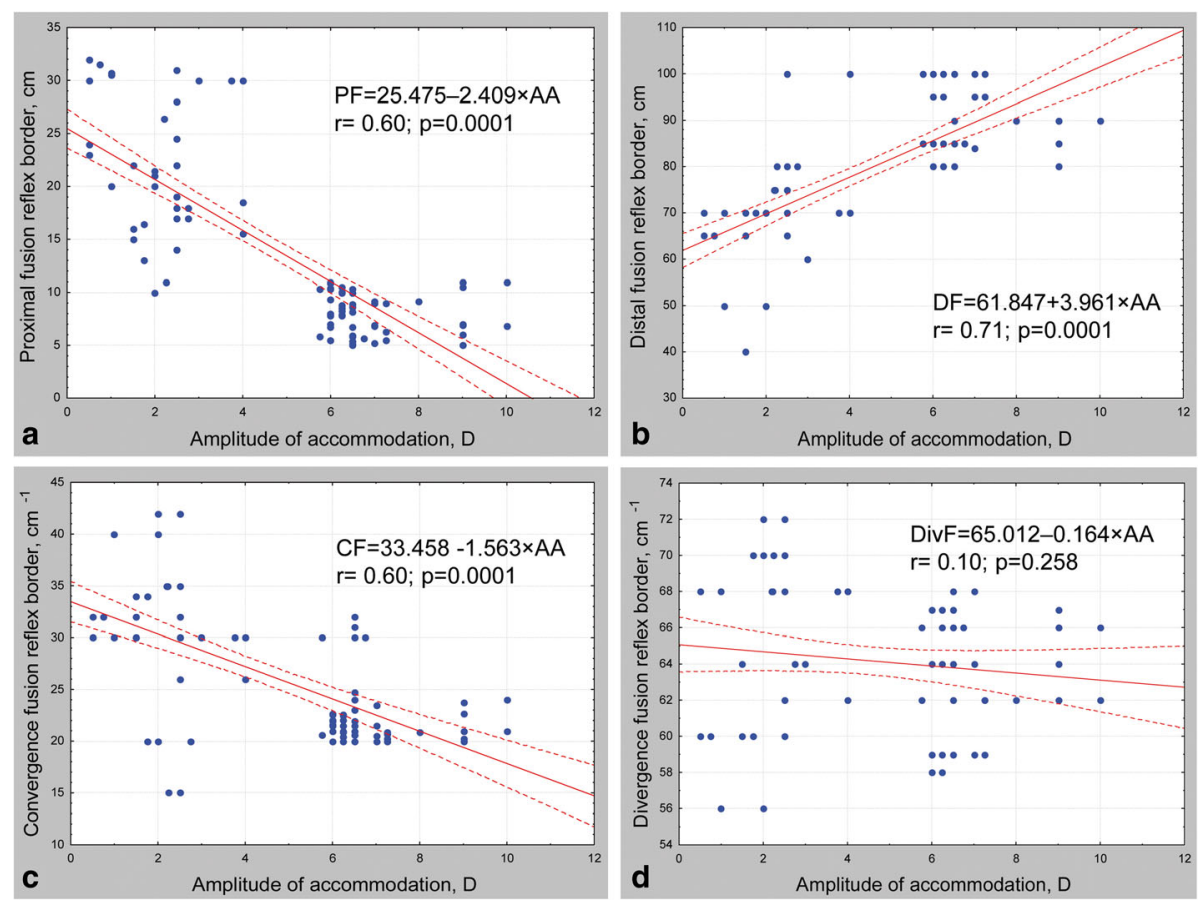

Fig. 4 Regressions between Fusion Reflex Borders and Accommodation Amplitude. a relationship between proximal fusion border and accommodation amplitude, $\mathbf{b}$ relationship between distal fusion border and accommodation amplitude, $\mathbf{c}$ relationship between convergence fusion border and accommodation amplitude, $\mathbf{d}$ relationship between divergence fusion border and accommodation amplitude

$456 \mathrm{~cm}^{2}$ ). All patients with presbyopia had a decreased fusion ability with the mean area of binocularity field at $174.4 \pm 87.7 \mathrm{~cm}^{2}$ (minimum $48 \mathrm{~cm}^{2}$, maximum $385 \mathrm{~cm}^{2}$ ). The regression between binocularity field area and accommodation amplitude is shown in Fig. 5.

It is interesting to note that $77 \%$ patients with presbyopia had binocular suppression in some grade, while $6 \%$ of patients had extreme decrease in the binocularity field area (Fig. 6).

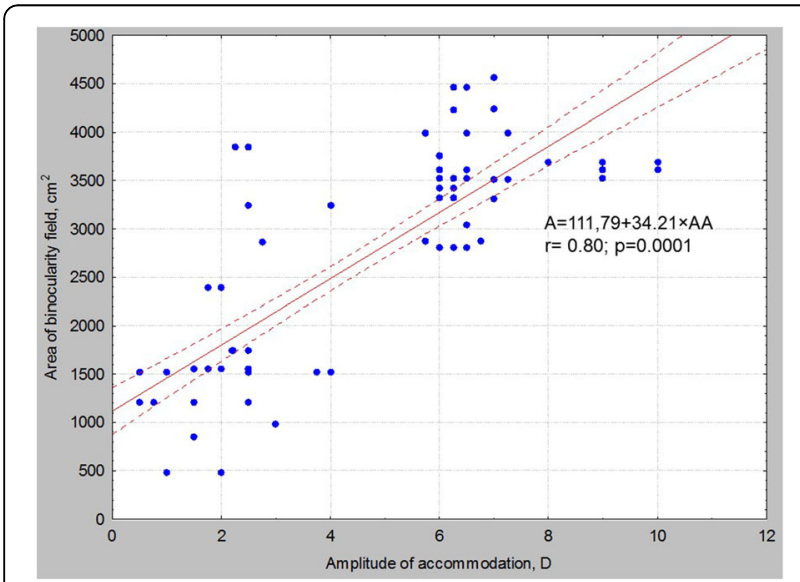

Fig. 5 Regressions between Binocularity Field Area and Accommodation Amplitude

\section{Intrasystem interactions}

The multivariate kinds of statistical analyses were used for the understanding of the vision reception transformation in presbyopia formation.

A Pearson correlation analysis of visual system parameters was made. The comparison of the correlation Pleiades (correlations with $P$-value equal or less than 0.001) within Control and Presbyopia Groups revealed a reduction in the strength of most relationships. The correlation Pleiades are represented in Fig. 7, where the positive correlations were shown as red arrows and the negative correlations as blue ones.

It is evident that young people without presbyopia have a much larger number of interdependencies between structural and functional indicators of the visual system than in patients with presbyopia. In young people, 25 close relationships were established, but in patients with presbyopia, there were only 6 such relationships. Instead of destroyed relationships, there was a new correlation between the width of the binocularity field and the implicit time of visual evoked potentials $(r=-0,7 ; p=0.001)$.

In the forward stepwise discriminant analysis, eight indices were selected for $100 \%$ discrimination of studied groups. The matrix of most informative variables for discrimination is represented in Table 4.

The separation between groups is not only due to the accommodation state but also to some other significant 


\section{People Distribution Depending on the Binocularity Field Area}
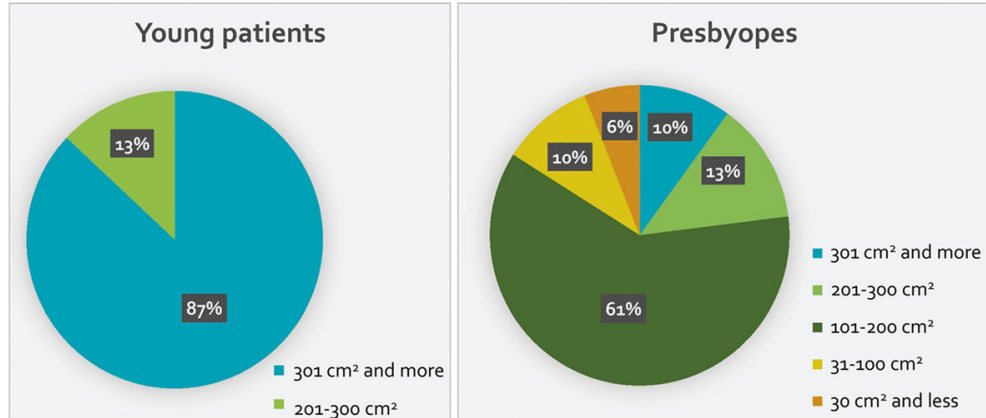

Fig. 6 Distribution of Patients Depending on the value of Binocularity Field Area

changes in the structural and functional parameters. The indicators of the tolerance show that all features are orthogonal and their contributions to the separation do not overlap.

The results of the discriminant analysis showed that the fusional ability made the high contribution in the separation of two groups. At the same time, the contribution of other sensory parameters in the division was less expressed.

\section{Discussion}

This research aimed to describe the transformation of the visual system functional organization during the presbyopia formation. The results of the study broaden our understanding of the presbyopia mechanisms. It was found that the structural and functional state of the visual system in middle-aged patients with presbyopia is significantly different from young people.

The reduction of the accommodation is significant, but not the only sign of visual transformation in patients with presbyopia. The increase in the number of optical errors despite the pupil tour decrease worsens the conditions for the formation of the retinal image. The formation of presbyopia is accompanied by the misalignment of visual sensory processing with varying degrees of functional defect severity (Fig. 8).

The decrease of the contrast sensitivity at frequencies below four cpd reflects the amplification of the visual system internal noise (at the level of receptive fields). Whereas the contrast sensitivity at high spatial frequencies is limited with optical parameters (aberrations, diffraction phenomenon or "sampling noise" of the visual image). The patients with presbyopia had the signs both internal noise and sampling noise (noise of signal processing). The change of temporal parameters of the visual system at middle age patients indicates the initial deficiency of interactions between neurons and the signs of the central nervous system fatigue. These changes can be viewed as signs of aging.

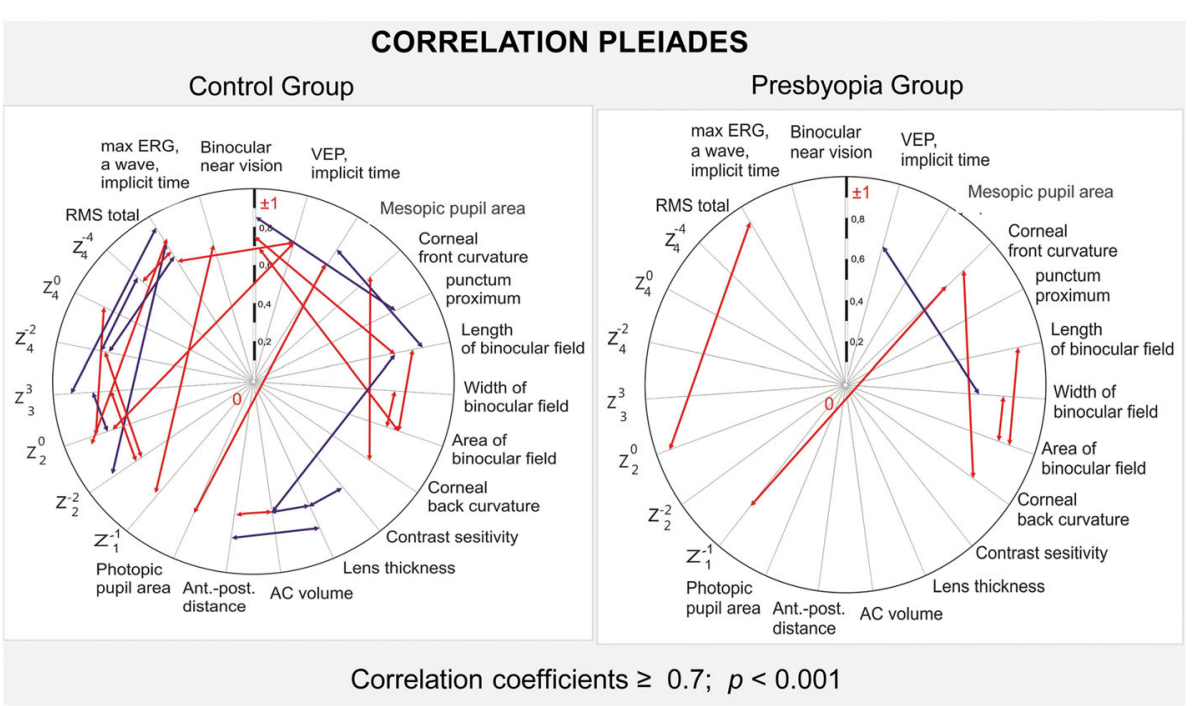

Fig. 7 Correlation Pleiades of Control and Presbyopia Groups 
Table 4 Matrix of most informative variables for discrimination studied groups

Discriminant Function Analysis Summary

Step 8, Wilks' Lambda:0.02771, approx. F (9.74) $=288.46$

Mahalanobis $\mathrm{D}^{2}=139.84, p<0,0001$

\begin{tabular}{|c|c|c|c|c|}
\hline Variables & Wilks' Lambda & F-remove (1.74) & $p$-level & Tolerance \\
\hline UNVA & 0.068917 & 110.0151 & 0.000001 & 0.621721 \\
\hline Proximal border of fusion field & 0.049343 & 57.7521 & 0.000001 & 0.667574 \\
\hline Amplitude of accommodation & 0.040528 & 34.2152 & 0.000001 & 0.619955 \\
\hline Binocularity area & 0.038421 & 28.5871 & 0.000001 & 0.567583 \\
\hline Coefficient corneal spherical aberration $Z_{4}^{0}$ & 0.037609 & 26.4206 & 0.000002 & 0.545072 \\
\hline Pupil diameter in photopic conditions & 0.033739 & 16.0866 & 0.000143 & 0.718888 \\
\hline Implicit time b-wave max ERG, msec & 0.030783 & 8.1942 & 0.005462 & 0.803496 \\
\hline CSS, frequency $3 \mathrm{cpd}$, units & 0.029672 & 5.2271 & 0.025101 & 0.850332 \\
\hline
\end{tabular}

The new data about binocular visual system activity was established. The processes of binocular interaction inhibition make a significant contribution to the misalignment of the visual perception. The area of binocularity field, where the disparate fusion is possible, was reduced twice. The variation of proximal fusion limit and a decrease of the binocularity field area are more serious than the variation in other sensor parameters.

On the one hand, this phenomenon may be a result of age-related changes in the neurons. On the other hand, the inhibition process can be motivated by the desire to liberate the body from the excessive flow of the visual information under the shortage of accommodation. The process of efferent synthesis is an active selection of information aimed to release biologically significant flows and is formed in such integral efferent excitations that are required by the body in a given situation.

Our results correspond to the relevant studies. GrangerDonetti revealed that majority of presbyopes had disorders of binocular cooperation in some degree due to a decrease in the slow convergence [42]. The accommodation amplitude decrease is accompanied by the increase of vergence

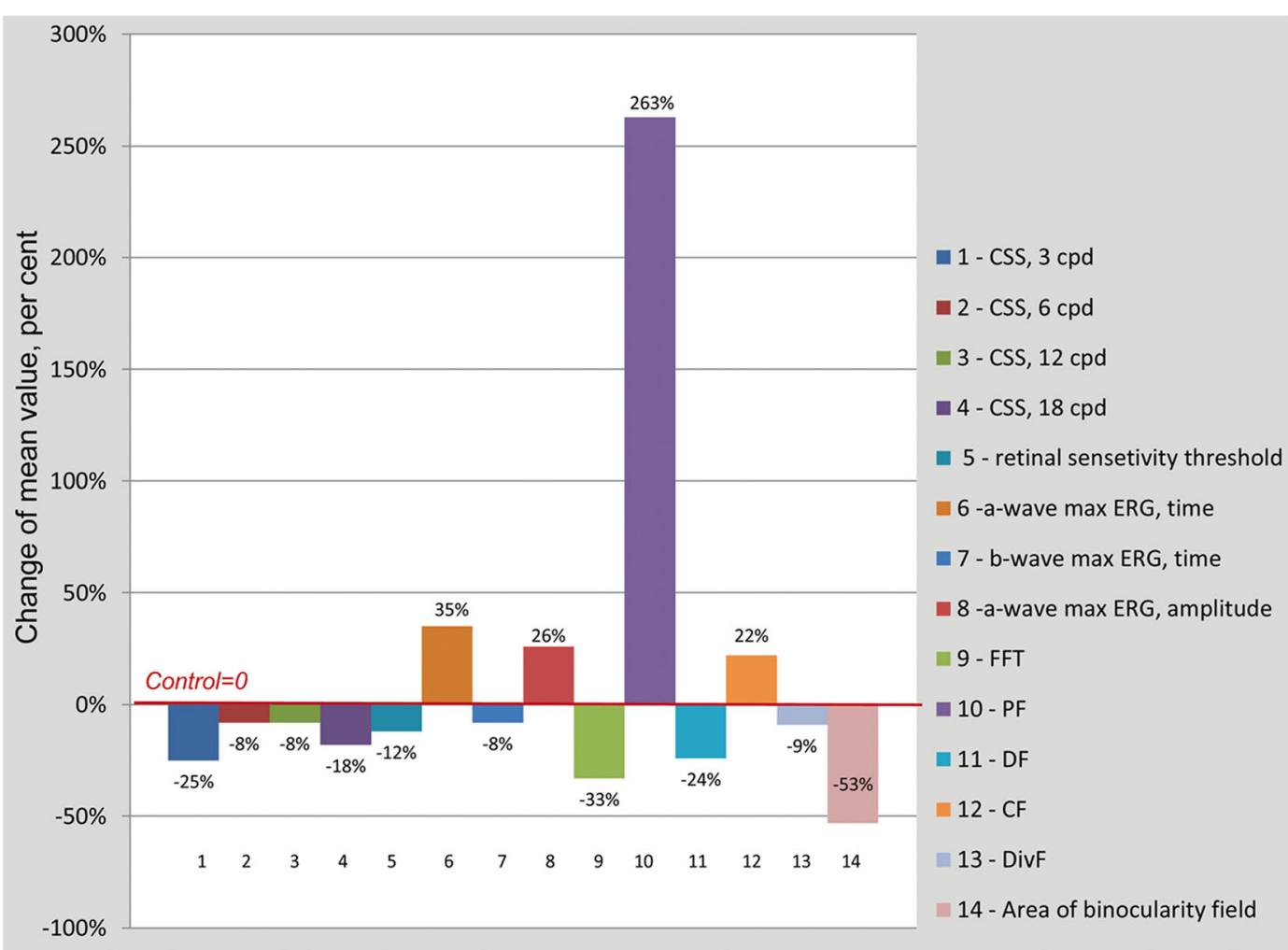

Fig. 8 The Changes of the visual parameters $(M)$ in patients with presbyopia in comparison with indicators of young people 
movement latency, the reduction of the vergence fusion and the speed of the fast vergence [43].

In this study, we analyzed data in people with the visual system that mostly meets the ideal. Even in this situation, $77 \%$ of presbyopia patients had binocularity shortage. In $6 \%$ of cases, there were profound signs of the deep inhibition processes. These data are likely useful in presbyopia surgery. The analysis of the surgery results using monovision or multifocal optical strategies in patients with an extreme deficit of binocularity is the next step of research.

\section{Conclusions}

The presbyopia formation is accompanied by a significant reorganization of the visual system activity and the creation of the new visual processing interactions. It was revealed that $77 \%$ of the presbyopia patients had binocularity shortage. The overall reduction of binocularity field area in extreme grade was seen in $6 \%$ of cases. These data may have implications for presbyopia surgery.

\section{Acknowledgements}

The authors are grateful to Isay M. Mikhalevich and Vladimir V. Malyshev for their help and advice.

\section{Funding}

The authors have no financial support and sponsorship.

\section{Authors' contributions}

OIR made substantial contributions to conception and design, analysis, and interpretation of data, total statistical analysis, AGS revised it critically for important intellectual content and supervision, TSM participated in data acquisition, drafted the manuscript. All authors read and approved the final manuscript.

\section{Competing interests}

The authors have no proprietary or commercial interests in the medical devices that are involved in this manuscript.

\section{Author details}

${ }^{1}$ Irkutsk branch of S. Fyodorov Eye Microsurgery Federal State Institution, Irkutsk, Russian Federation. ${ }^{2}$ Irkutsk State Medical University, Irkutsk, Russian Federation.

\section{Received: 31 August 2016 Accepted: 4 January 2018}

Published online: 25 January 2018

\section{References}

1. Belville JK, Smith RJ. Presbyopia surgery. New York: SLACK; 2006.

2. Hashemi $H$, Khabazkhoob M, Jafarzadehpur E, Mehravaran S, Emamian MH, Yekta A, et al. Population-based study of presbyopia in Shahroud, Iran. Clin Exp Ophthalmol. 2012;40:863-8.

3. Hudson C. How to succeed with multifocal contact lenses. Optometry Today. 2011;51:2

4. Varma R, Wang MY, Ying-Lai M, Donofrio J, Azen SP; Los Angeles Latino eye study group. The prevalence and risk indicators of uncorrected refractive error and unmet refractive need in Latinos: the Los Angeles Latino Eye Study. Invest Ophthalmol Vis Sci. 2008;49:5264-73.

5. Pallikaris IG. Presbyopia surgery. In: Pallikaris I, Plainis S, Charman WN, editors. Presbyopia: origins, effects, and treatment. Danvers: Slack; 2012. p. 141-2.

6. Nijkamp MD, Dolders MG, de Brabander J, van den Borne B, Hendrikse F, Nuijts RM. Effectiveness of multifocal intraocular lenses to correct presbyopia after cataract surgery: a randomized controlled trial. Ophthalmology. 2004:111:1832-9.

7. Bellucci R. Multifocal intraocular lenses. Curr Opin Ophthalmol. 2005;16:33-7.
8. Chang DF. Mastering refractive IOLs. The art and science. Thorofare, NJ: SLACK; 2008.

9. Gierek-Ciaciura S, Cwalina L, Bednarski L, Mrukwa-Kominek E. A comparative clinical study of the visual results between three types of multifocal lenses. Graefes Arch Clin Exp Ophthalmol. 2010;248:133-40.

10. Cochener B, Lafuma A, Khoshnood B, Courouve L, Berdeaux G. Comparison of outcomes with multifocal intraocular lenses: a meta-analysis. Clin Ophthalmol. 2011;5:45-56.

11. Friedrich R. Intraocular lens multifocality combined with the compensation for corneal spherical aberration: a new concept of presbyopia-correcting intraocular lens. Case Rep Ophthalmol. 2012;3:375-83.

12. Lichtinger A, Rootman DS. Intraocular lenses for presbyopia correction: past, present, and future. Curr Opin Ophthalmol. 2012;23:40-6.

13. Calladine D, Evans JR, Shah S, Leyland M. Multifocal versus monofocal intraocular lenses after cataract extraction. Cochrane Database Syst Rev. 2012;9:CD003169.

14. Javitt JC, Steinert RF. Cataract extraction with multifocal intraocular lens implantation: a multinational clinical trial evaluating clinical, functional, and quality-of-life outcomes. Ophthalmology. 2000;107:2040-8.

15. Tan N, Zheng D, Ye J. Comparison of visual performance after implantation of 3 types of intraocular lenses: accommodative, multifocal, and monofocal. Eur J Ophthalmol. 2014;24:693-8.

16. Bassam A, Donnenfeld E. Bonus feature: IOL Explantation: indications and strategies for multifocal IOL explantation. Cataract and Refractive Surgery Today. 2011:4:18-20.

17. Bucci FA Jr. "Vaseline Vision Dysphotopsia" and Explantation of the ReSTOR Multifocal Implant. Invest Ophthalmol Vis Sci. 2007:48(13):3119.

18. Fernández-Buenaga R, Alio JL, Muñoz-Negrete FJ, Barraquer Compte RI, Alio-del Barrio JL. Causes of IOL explantation in Spain. Eur J Ophthalmol. 2012;22:762-8

19. Shimizu K, Ito M. Dissatisfaction after bilateral multifocal intraocular lens implantation: an electrophysiology study. J Refract Surg. 2011;27:309-12.

20. Woodward MA, Randleman JB, Stulting RD. Dissatisfaction after multifocal intraocular lens implantation. J Cataract Refract Surg. 2009;35:992-7.

21. Timiras PS. Physiological basis of aging and geriatrics. 4th ed. Berkeley: Informa Healthcare; 2007.

22. Glasser A, Campbell MC. Biometric, optical and physical changes in the isolated human crystalline lens with age in relation to presbyopia. Vision Res. 1999:39:1991-2015.

23. Croft MA, McDonald JP, Katz A, Lin TL, Lütjen-Drecoll E, Kaufman PL. Extralenticular and lenticular aspects of accommodation and presbyopia in human versus monkey eyes. Invest Ophthalmol Vis Sci. 2013;54:5035-48.

24. Croft MA, Kaufman PL. Role of the ciliary muscle and zonula in accommodation and presbyopia. In: Pallikaris I, Plainis S, Charman WN, editors. Presbyopia: origins, effects, and treatment. Danvers: Slack; 2012. p. 69-76.

25. Anokhin PK. Biology and neurophysiology of the conditioned reflex and its role in adaptive behavior. New York: Pergamon Press; 1974

26. Meerson FZ. Adaptation, stress and prophylaxis. Berlin: Springer-Verlag; 1984

27. Sudakov KV. The theory of functional systems: general postulates and principles of dynamic organization (dedicated to the Anokhin Centenary). Integr Physiol Behav Sci. 1997;32:392-414.

28. Rozanova OI, Shchuko AG, Mikhalevich IM, Malyshev W. [Regularities and mechanisms of visual perception transformation in presbyopia development]. Vestn Oftalmol. 2011;127:17-20.

29. Owsley C. Aging and vision. Vis Res. 2011:51:1610-22.

30. Ciuffreda KJ, Thiagarajan P. Presbyopia and the vergence system. In: Pallikaris I, Plainis S, Charman WN, editors. Presbyopia: origins, effects, and treatment. Danvers: Slack; 2012. p. 103-9.

31. Werner JS, Schefrin BE, Bradley A. Optics and vision of the aging eye. In: Bass M, Enoch M, Lakshminarayanan V, editors. Handbook of Optics. Vol. III. New York: McGraw Hill Inc; 2010

32. Andersen GJ. Aging and vision: changes in function and performance from optics to perception. Wiley Interdiscip Rev Cogn Sci. 2012:3:403-10.

33. Laframboise S, De Guise D, Faubert J. Effect of aging on stereoscopic interocular correlation. Optom Vis Sci. 2006:83:589-93.

34. Shafiee D, Jafari AR, Shafie AA. Correlation between Interpupillary Distance and stereo acuity. Bull Env Pharmacol Life Sci. 2014:3(12):26-33.

35. Eom Y, Song JS, Ahn SE, Kang Y, Suh YW, Oh J, et al. Effects of interpupillary distance on stereoacuity: the Frisby Davis distance stereotest versus a 3dimensional distance stereotest. Jpn J Ophthalmol. 2013;57:486-92. 
36. Pavlin CJ, Foster FS. Ultrasound biomicroscopy of the eye. New York: Springer-Verlag; 1995.

37. Mogilev LN. Mechanisms of spatial vision. Leningrad: Nauka; 1982. (in Russian)

38. Rabitchev IE. The mechanisms of binocular function correction at different forms of strabismus. J Fr d'Orthoptique. 1998;30:153-9. (in French)

39. Hofstetter HW. Dictionary of Visual Science and Related Clinical Terms. Boston: Butterworth-Heinemann; 2000.

40. Rychkova SI, Ninio J. Paradoxical fusion of two images and depth perception with a squinting eye. Vision Res. 2009;49:530-5.

41. By Shchuko AG, Malyshev W. Theoretical and clinical binarimetry. Novosibirsk: Nauka; 2006. (in Russian)

42. Granger-Donetti B. Central suppression at near vision in presbyopic subjects. Perception. 2006;35(Suppl 1):172.

43. Ciuffreda KJ. Accommodation, pupil, and presbyopia. In: Benjamin WJ, editor Borish's clinical refraction. St. Louis: Buterworth Heinemann; 2006. p. 93-144.

Submit your next manuscript to BioMed Central and we will help you at every step:

- We accept pre-submission inquiries

- Our selector tool helps you to find the most relevant journal

- We provide round the clock customer support

- Convenient online submission

- Thorough peer review

- Inclusion in PubMed and all major indexing services

- Maximum visibility for your research

Submit your manuscript at www.biomedcentral.com/submit
Biomed Central 